\title{
Wolfberry tree dual-model detection method and orchard target-oriented fertilization system based on photoelectric sensors
}

\author{
Shuo Yang ${ }^{1,2}$, Changyuan Zhai ${ }^{1,2,3^{*}}$, John Long ${ }^{3}$, Bo Zhang ${ }^{1}$, Hanzhe $\mathrm{Li}^{1}$ \\ (1. College of Mechanical and Electronic Engineering, Northwest A\&F University, Yangling 712100, China; \\ 2. Key Laboratory of Agricultural Internet of Things, Ministry of Agriculture and Rural Affairs, Yangling, Shaanxi 712100, China; \\ 3. Department of Biosystems and Agricultural Engineering, Oklahoma State University, Stillwater, OK 74078, USA)
}

\begin{abstract}
Orchard target-oriented fertilizing with on-board sensor technology can improve fertilizer efficiency and reduce environmental pollution. Photoelectric sensors are widely used for object detection because of their low cost and fast response time. This paper presents a Wolfberry tree dual-model detection method and the design of an orchard target-oriented variable-rate fertilization system based on photoelectric sensors. The dual-model detection method includes the Trunk Detection Model (TDM) and Canopy Detection Model (CDM), which can be applied for Wolfberry orchards at the green cluster and mature stages, respectively. A target-oriented fertilization system was designed using the dual-model method, and tested in the lab and Chinese Wolfberry orchard. The laboratory test results showed that the average center offset distances on the condition of detecting trunks, continuous canopies, and discontinuous canopies were $4.1 \mathrm{~cm}, 9.1 \mathrm{~cm}$ and $13.1 \mathrm{~cm}$, respectively. The system could ignore the signals from canes when their diameters were less than $16 \mathrm{~mm}$, and also could determine the gaps within a tree when they were less than $21 \mathrm{~cm}$. The orchard test results showed that the system accomplished target-oriented fertilization 95 times for 92 trees at the mature stage. The results indicated that the dual-model detection method could be used for Wolfberry trees or other trees with similar canopy changes at different growth stages.

Keywords: orchard fertilizer, target-oriented fertilization, variable rate fertilization, photoelectric sensor, wolfberry orchard DOI: $10.25165 /$ j.ijabe.20181104.3614
\end{abstract}

Citation: Yang S, Zhai C Y, Long J, Zhang B, Li H Z. Wolfberry tree dual-model detection method and orchard target-oriented fertilization system based on photoelectric sensors. Int J Agric \& Biol Eng, 2018; 11(4): 65-73.

\section{Introduction}

Variable Rate Fertilization (VRF), with the advantages of precise fertilizer rates and accurate fertilizing position, can increase fertilizer utilization and save costs ${ }^{[1-3]}$. There are two main VRF systems: prescription map-based and real-time sensor-based ${ }^{[4-10]}$. The former system, which divides a crop field into small grids and applies fertilizer depending on the prescription map, has a widespread use for crop field fertilization ${ }^{[11-14]}$. In the latter system, the data from the sensor are collected, processed, and interpreted by an on-board computer in real-time to guide fertilization. In an orchard, fruit trees are discontinuously planted and different from each other in trunk location and canopy size. Sensor-based VRF systems are widely applied in orchards. Schumann introduced a VRF method using sensors to obtain citrus canopy information ${ }^{[15]}$. This method made the fertilization accurate by considering the differences among individual citrus trees. In order to acquire the geometrical characterization of orchard trees to guide the fertilization, many on-board sensors were investigated. The sensors mainly included digital photographs ${ }^{[16-18]}$,

Received date: 2017-07-02 Accepted date: 2018-01-29

Biographies: Shuo Yang, $\mathrm{PhD}$ candidate, research interests: intelligent equipment for agriculture, Email: yangshuosjz@163.com; John Long, Assistant Professor, research interest: agriculture machinery systems, Email: john.m.long@okstate.edu; Bo Zhang, MS, research interests: intelligent equipment for agriculture, Email: zhangbo 609@163.com; Hanzhe Li, PhD candidate, research interests: intelligent equipment for agriculture, Email: lihanzhe187@163.com.

*Corresponding author: Changyuan Zhai, Associate Professor, research interests: precision agriculture. No. 22, Xinong Road, Yangling 712100, Shaanxi, China. Tel: +86-29-87092391, Email: zhaichangyuan@nwsuaf.edu.cn. ultrasonic sensors ${ }^{[19-23]}$, photoelectric sensors ${ }^{[24,25]}$, and LIDAR sensors ${ }^{[26-30]}$. Digital photograph technology estimates tree characteristics with low cost digital cameras, but requires specific lighting conditions. Ultrasonic sensors are more robust and typically at a lower price point than digital cameras. Due to the ultrasonic beam angle, there will be a lower level of accuracy when detecting targets with uneven profiles. LIDAR sensors can generate $3 \mathrm{D}$ digitalized images of fruit trees with high precision, but the system requires high storage capacity and longer processing time. Photoelectric sensors have the advantages of quick response, higher precision and low prices. It can detect a little orchard target, whose diameter could be as small as $15.7 \mathrm{~mm}^{[31]}$. These features benefit the fruit tree detection when the fruit tree has a thin shape at the green cluster stage and a luxuriant canopy at the mature stage in a growing season. The low price advantage of the sensors reduces the cost of the VRF system and raises its competitiveness in application in agriculture.

Over 2.6 million $\mathrm{hm}^{2}$ of Wolfberry trees are planted in Qinghai Province of China. Wolfberry trees are a deciduous woody plant belonging to the genus Lycium. Their canopies change much during different growth stages, which makes it more difficult to detect.

The objective of this paper is to investigate a dual-model method for Wolfberry tree detection at different growth stages and design an orchard target-oriented variable-rate fertilization system based on photoelectric sensors.

\section{Materials and methods}

\subsection{Wolfberry orchard}

The Chinese Wolfberry tree needs fertilization at its two important stages: the green cluster stage and mature stage. At the 
green cluster stage, the Chinese Wolfberry tree canopy has a few leaves with branches scattered, and the tree trunk can be clearly seen. At the half height of the trunk, there are no or few low-hanging canes with diameters much smaller than that of the tree trunk (Figure 1a). However, at the mature stage, the tree canopy is filled with leaves and fruits, and the trunk is covered by many long low-hanging canes with thick leaves (Figure 1b). When fertilizing, a certain amount of fertilization needs to be put under ground near each trunk.

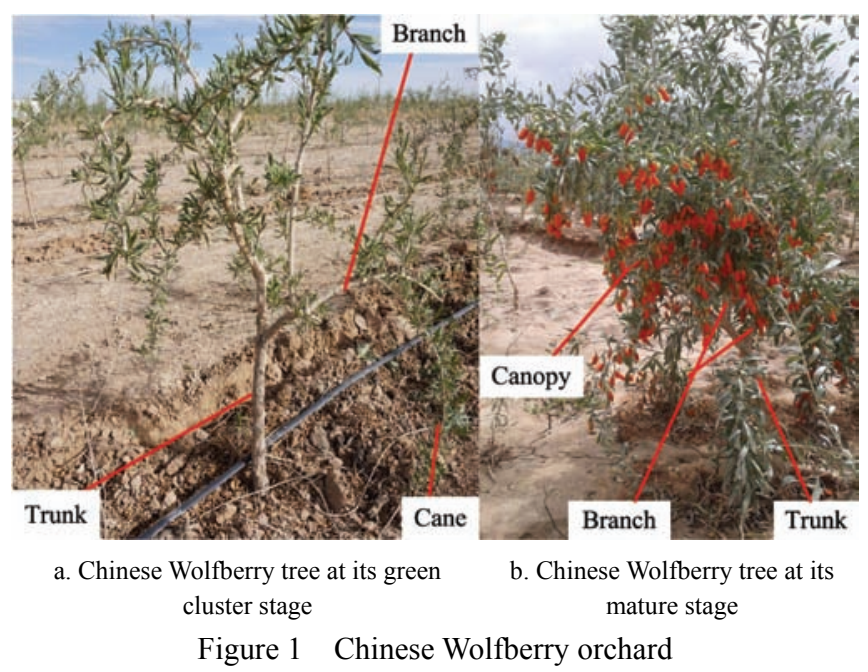

\subsection{Dual-model Wolfberry tree detection method}

The Chinese Wolfberry tree characteristic is different at each growth stage. At the green cluster stage, it is hard to distinguish trees by detecting the canopies with only a few scattered branches. While at the mature stage, the low-hanging canes make it difficult to correctly detect the trunks. Zhai et al. ${ }^{[24]}$ presented a Wolfberry orchard fertilizer control system, which could detect tree trunks in real-time for target-oriented fertilization based on photoelectric sensors (Figure 2). The results showed that the system could correctly detect and drop fertilizer to 97 Wolfberry trees out of 100 for trees in the early green cluster stage. However, the system cannot be used in Wolfberry orchards at the mature stage when the trunks are covered by low-hanging canes and leaves.

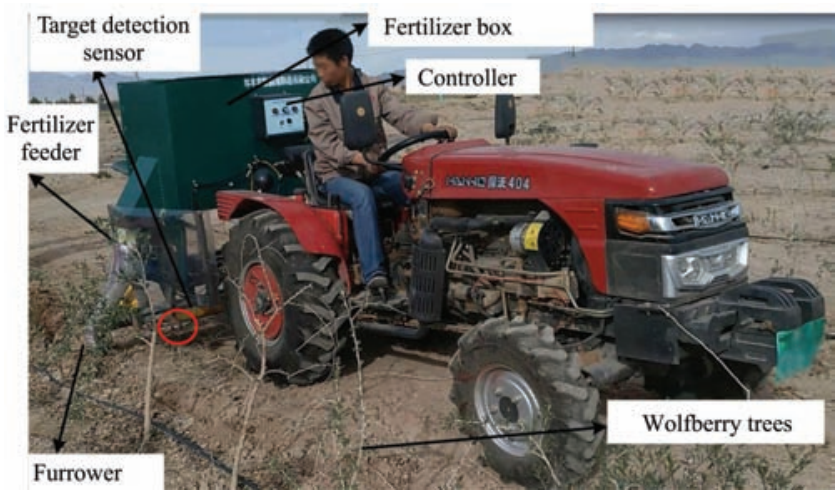

Figure 2 Target-oriented fertilization by detecting tree trunks based on photoelectric sensors

A dual-model detection method based on photoelectric sensors was proposed, which had two function models: the Trunk Detection Model (TDM) for Chinese Wolfberry tree at the green cluster stage, and the Canopy Detection Model (CDM) used at the mature stage. According to the local agronomic requirements, the difference distance value between the center point of fertilization location and the center point of the tree should be arrange from $-20 \mathrm{~cm}$ to $20 \mathrm{~cm}$.
In the TDM, a photoelectric sensor was adjusted to the half average height (about $20 \mathrm{~cm}$ above the ground) of the tree trunks (Figure 3a). When the fertilizer applicator passed by a tree, the trunk or the small low-hanging canes would trigger the photoelectric sensor. The controller of the fertilization system analyzed the data from the sensor, discarded the information from the small low-hanging canes, and identified the location of the trunk. According to the investigation on May 22, 2015 at the Haixi district of Qinghai Province, the trunk diameters of wolfberry trees were more than $25 \mathrm{~mm}$ with an average of $29 \mathrm{~mm}$. And on August 13, 2015 at the Hainan district of Qinghai Province, the trunk diameters of wolfberry trees were more than $26 \mathrm{~mm}$ with an average of $28.3 \mathrm{~mm}$. The diameter of low-hanging cane was less than $10 \mathrm{~mm}$. So the trunk width threshold was set as $20 \mathrm{~mm}$, which is close to the middle of the range of $10-25 \mathrm{~mm}$, and is the only integer number if the unit is $\mathrm{cm}$. Any object with a width larger than the threshold would only be determined to be a tree trunk.

In the CDM, two or three photoelectric sensors were placed at different heights toward tree canopies (Figure 3b). The threshold of the gap distance between the gap in one tree and the gap in two adjacent trees was $22 \mathrm{~cm}$ according to the investigation on standardized wolfberry orchard that the maximum gap in a tree is $20 \mathrm{~cm}$. If the length of a gap was less than the threshold, the gap would be determined to be within a tree. Otherwise, it would be determined to be between two adjacent trees. If there was no overlap between adjacent canopies, the tree would be separated by the gap between two adjacent trees. If the adjacent canopies overlapped, the tree would be separated according to the average tree width which was set on the controller.
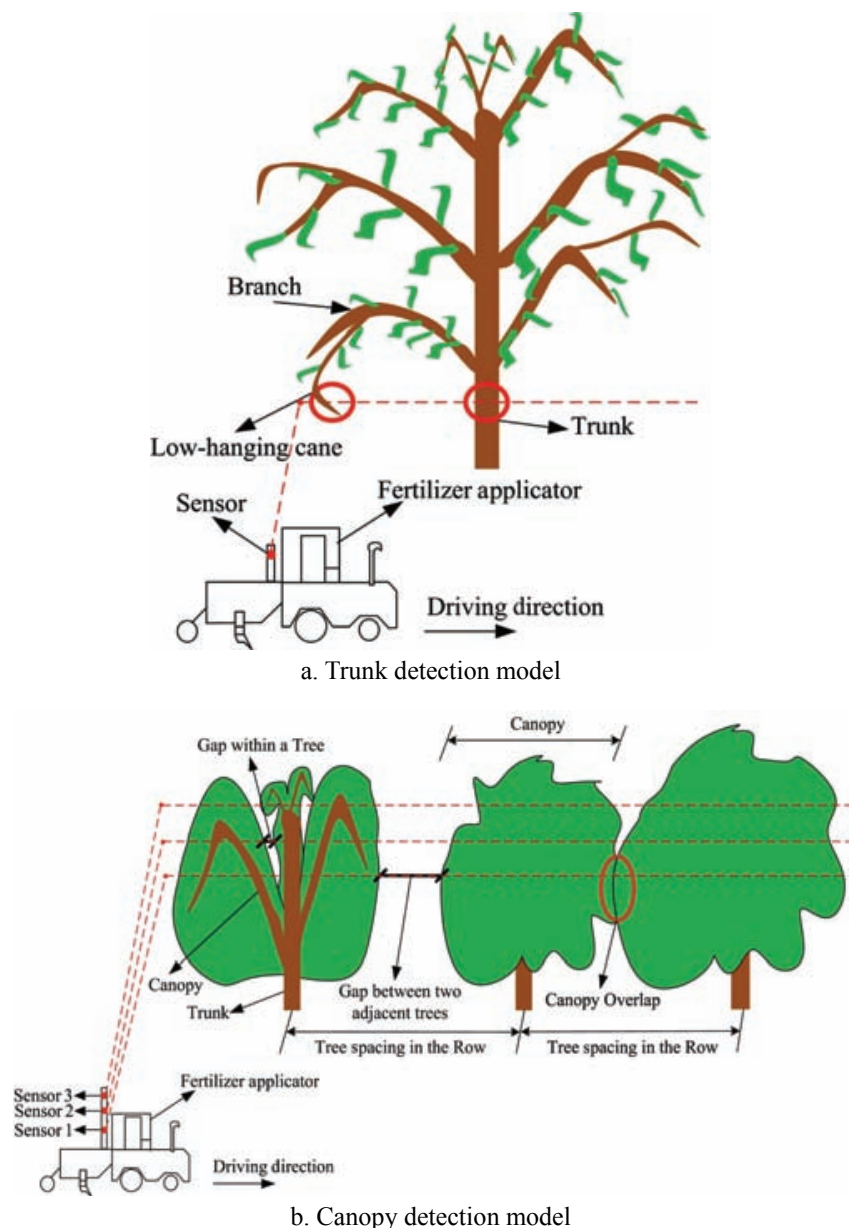

Figure 3 Dual-model Wolfberry tree detection method 


\subsection{Control system design}

\subsubsection{Overall design of the control system}

An orchard variable-rate fertilization system was designed based on the dual-model tree detection method, which mainly included a controller, a target detection system, a fertilizer feeder, a fertilizer dropping sensor, and a speed sensor (Figure 4). In the TDM, the system only used one sensor in each side. In the CDM, the system used 1-3 sensor(s) on each side. The photoelectric sensor(s) was/were vertically mounted on a fertilizer applicator to detect trees. The photoelectric sensors were set at the both side of the vehicle and worked at the same time. Those sensors in one side provided the detection signal for fertilization decision for the same side. The fertilizer feeder had six fertilizer flute wheels with a central angle of $60^{\circ}$ and a volume of $200 \mathrm{~mL}$. A $60^{\circ}$ Geneva mechanism was used in the transmission system of the fertilizer feeder. Each flute wheel would revolve $60^{\circ}$ when the motor made a rotation of $360^{\circ}$ (detailed structure information refers to Zhai et al. $\left.{ }^{[24]}\right)$. The fertilizer dropping sensor was set in the outlet of the fertilizer ejector to detect the fertilizer dropping. The speed sensor detected the bolts of the ground wheel to get applicator speed. The controller could read the Fertilizer-Volume setting and Tree-Width setting, deal with speed signals and target signals to locate the center of a tree, drive the motor to eject fertilizer, and send out alarm signals if the fertilizer was dropping in an incorrect way.

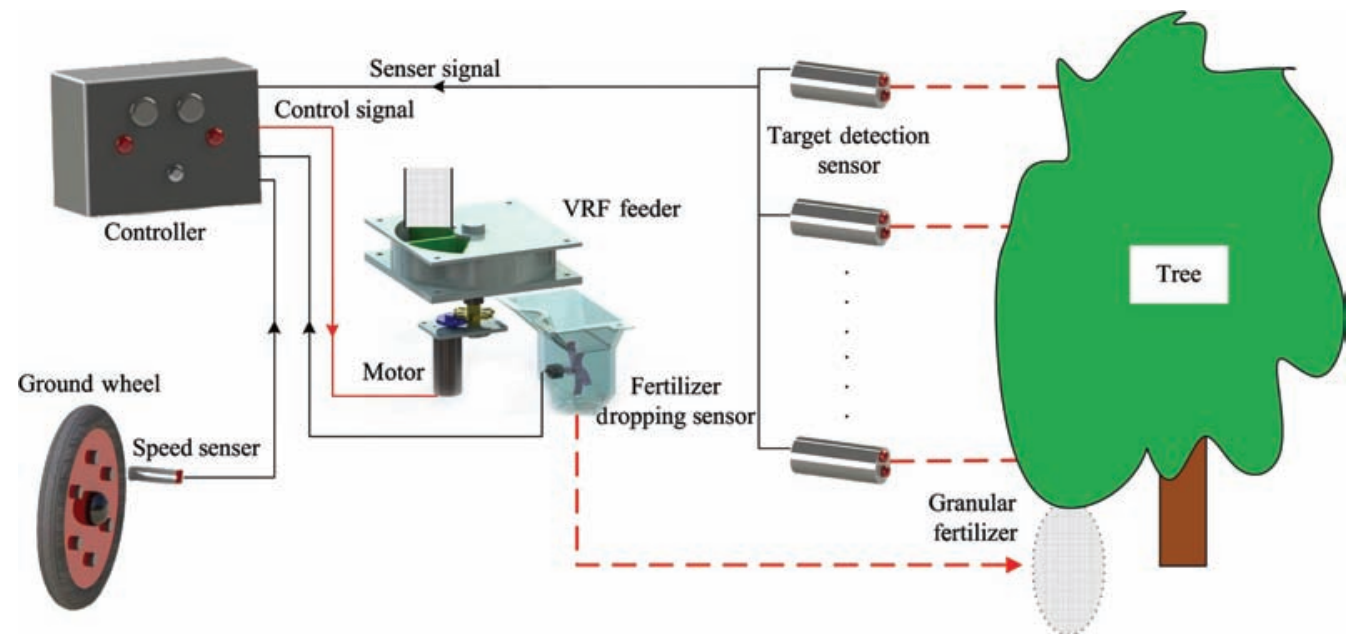

Figure 4 Overall design of the control system

\subsubsection{Design of the controller}

A controller was designed based on a Micro Controller Unit (MCU) of STC12C5A60S2, which could process fertilizing decisions for both left and right sides at the same time (Figure 5). Two potentiometer knobs with six distinct positions were set in the operation interface of the controller. One of them named "Fertilizer-Volume knob" was used to set the amount of the fertilizer needed per tree. The amount ranged from $0.4-1.0 \mathrm{~kg} /$ tree. The fertilizer bulk density was approximately $1 \mathrm{~g} / \mathrm{cm}^{3}$. The six distinct positions of the Fertilizer-Volume knob represented 0$1000 \mathrm{~cm}^{3}$ granule fertilizer with an increment of $200 \mathrm{~cm}^{3}$. The other one named "Tree-Width knob" was to set the average width of tree canopies. The Tree-width value ranged at 0.3-1.5 m. The six distinct positions of the Tree-Width knob represented 0-1.5 m with an increment of $0.3 \mathrm{~m}$. The settings of the potentiometer knobs were converted into voltage signals using a voltage division circuit, and then sent to the built-in high speed A/D converter of the MCU. The controller was powered by a vehicle power supply (DC 12V). The nominal voltage of the MCU was 3.5-5.5 V. A buck converter was designed to convert the DC $12 \mathrm{~V}$ to the DC $5 \mathrm{~V}$ for the MCU. The sensor system consisted of 2-6 target detection sensors (photoelectric sensor, FKB30E23NPK, Beijing Beijialai Industrial Control Technology \& Trade Center, Beijing), a speed sensor (approach switch sensor, E2E-X10ME1-Z, Omron, Japan), and two self-designed fertilizer dropping sensors (24). The target detection sensor and speed sensor were powered by $\mathrm{DC} 12 \mathrm{~V}$, and output a $12 \mathrm{~V}$ pulse signal. The fertilizer dropping sensor was powered by DC $5 \mathrm{~V}$, and output a $5 \mathrm{~V}$ pulse signal. The signal(s) of the 1-3 sensor(s) was (were) inputted into an OR-logic gate circuit to generate a final output signal. If none of the sensor(s)

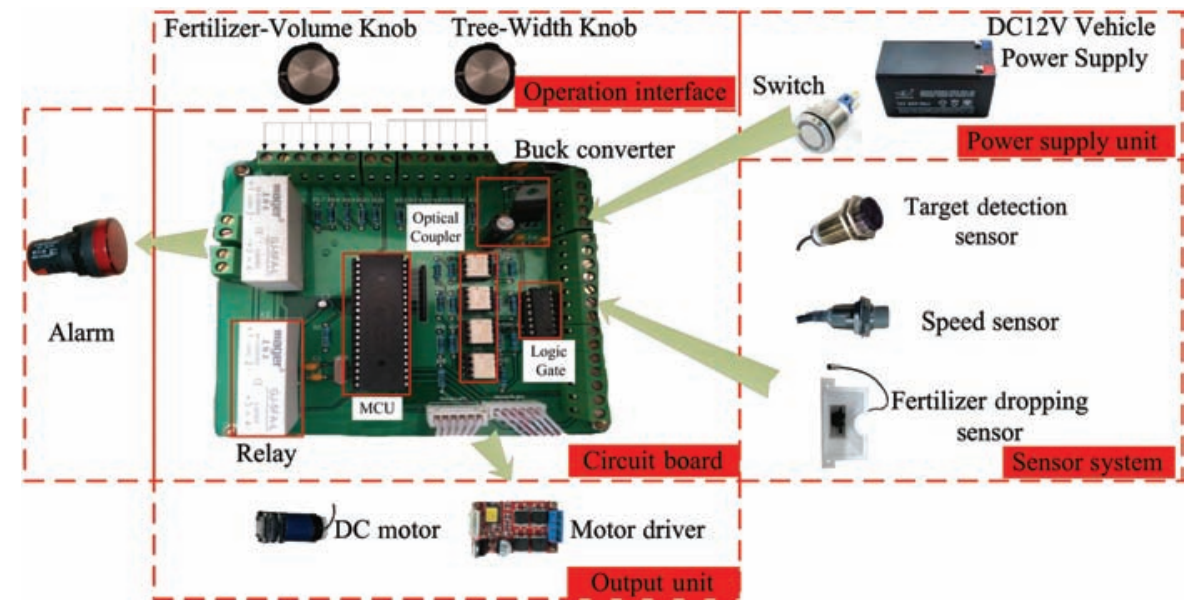

Figure 5 Schematic diagram of the hardware of the controller 
detects a tree, the OR-logic gate circuit would output a signal of "No Trees". Otherwise, the circuit would output a "Have a Tree" signal. Two DC motors and two alarms were controlled by the MCU using a motor driver and two relays, respectively. The signal of all the sensors and the motors was insulated from the signal of the MCU by optical couplers. On the console panel of the controller, there were a Fertilizer-Volume knob, a Tree-Width knob, two left and right alarm lights, a set of fuse and holder, and a power switch. If the Tree-Width setting was 0 , the controller would work in the TDM model. Otherwise, the controller would be in the CDM model.

\subsubsection{Controller software design}

A dual-model program based on the dual-model detection method was designed (Figure 6). The system started and was initialized after the controller was powered on. The system received speed signal from the speed sensor and calculated the ground speed using the following equation.

$$
v=\frac{\pi d_{0}}{N t_{0}}
$$

where, $v$ is the ground speed, $\mathrm{m} / \mathrm{s} ; d_{0}$ is the diameter of the ground wheel, $\mathrm{m} ; N$ is the number of the bolts on the ground wheel; and $t_{0}$ is the time between two adjacent sensor pulses, s. The program read the settings of the Fertilizer-Volume and Tree-Width. After acquiring the Tree-Width setting, the dual-model system would determine which model should be executed. If the value of the Tree-Width equaled zero, the system would choose the TDM model, otherwise, it would choose the CDM model. In the TDM, the system waited until the target was detected. The width of a target would be calculated as follows.

$$
D=v \times t_{1}
$$

where, $D$ is the diameter of the target, $\mathrm{m} ; t_{1}$ is the time of target detection, s. As mentioned in the section 2.1, the diameter of a cane was always much smaller than the diameter of a trunk. The program determined the detection target to be a cane or trunk according to the value of $D$. If it was a cane, the system would ignore the signal. If it was a trunk, the system would analyze the trunk location and after a certain time, $t_{2}$, start ejecting fertilizer. After $t_{3}$, the system would stop ejecting fertilizer. The time $t_{2}$ and $t_{3}$ were calculated as follows.

$$
\begin{aligned}
& t_{2}=\frac{l_{0}}{v}-t_{4} \\
& t_{3}=t_{2}+t_{5}
\end{aligned}
$$

where, $l_{0}$ is the horizontal distance between the photoelectric sensor and the furrower, $\mathrm{m}$; which is $1 \mathrm{~m}$ in this paper; $t_{4}$ is the time needed for the fertilizer to drop from the exit of the feeder to the ground, $\mathrm{s}$; which is $1 \mathrm{~s}$ in this paper; $t_{5}$ is the fertilizer ejection time.

In the CDM model, the system set the canopy start flag to be true after it detected a target. When a gap occurred, the system calculated the width of the gap using the following equation.

$$
C=\frac{\pi d_{0}}{N} n_{0}
$$

where, $C$ is the width of a gap or a canopy, in $\mathrm{m} ; n_{0}$ is the count of the speed sensor pules during a gap or a canopy.

If it was the gap between two adjacent trees, the canopy end flag would be set true. Otherwise, the canopy width would be calculated using Equation (5). When the canopy width was greater than the Tree-Width setting, the canopy end flag would be set true. Then, the system analyzed the center of the canopy and cleared the canopy start and end flags. The distance between the center of the canopy and the furrower, $l_{1}$, was calculated as follows.

$$
l_{1}=l_{0}-\frac{l_{2}}{2}
$$

where, $l_{2}$ is the Tree-Width setting, in $\mathrm{m}$. In the CDM, the fertilizer ejection start time, $t_{2}$, was calculated as follows.

$$
t_{2}=\frac{l_{1}}{v}-t_{4}
$$

The calculation of the fertilizer ejection stop time, $t_{3}$, in the CDM is the same as that in the TDM. During fertilizer ejecting, the system monitored the fertilizer dropping. If the fertilizer was not dropping correctly, the system would alarm. The system continuously ran until it was stopped by the user.

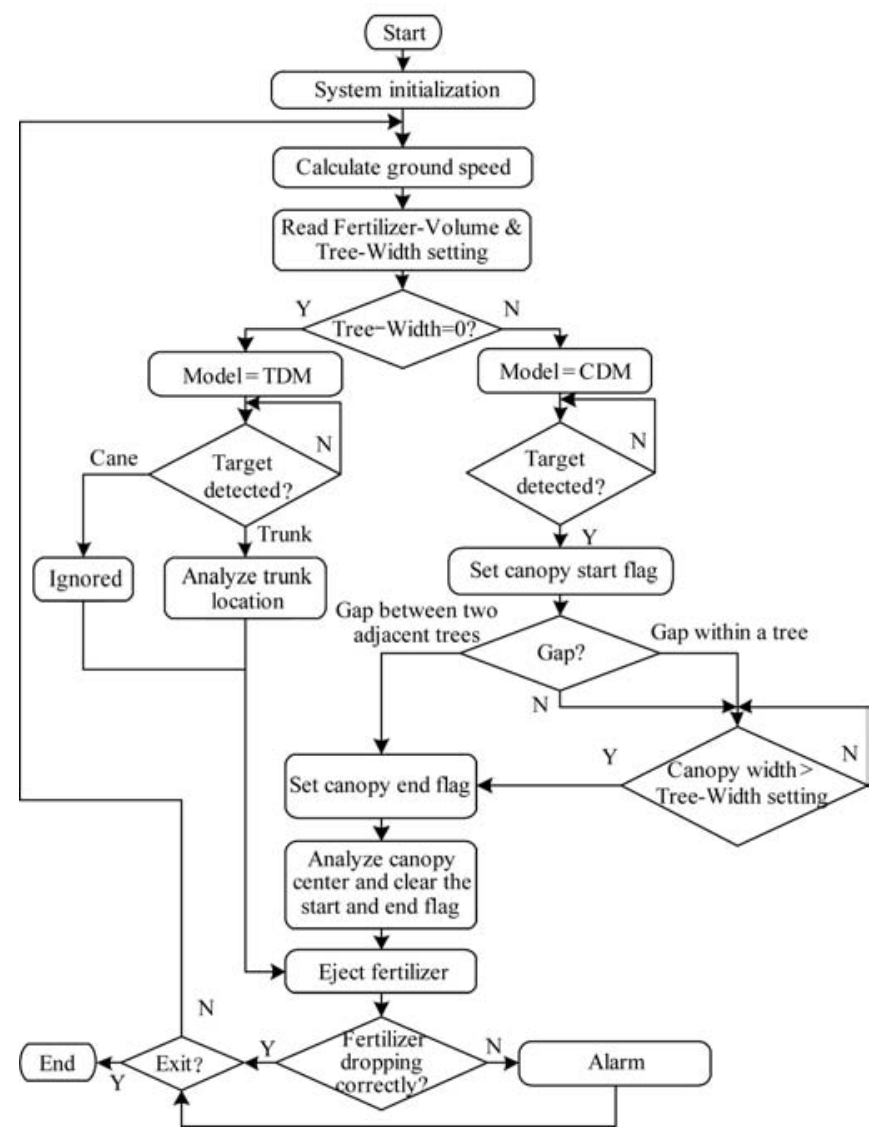

Figure 6 Flow chart of the controller software

\subsection{Experimental platform}

To simulate orchard target-oriented fertilization, an experimental platform was designed (Figure 7). An experiment cart was built, which consisted of an aluminum rectangular frame with a size of $1.3 \mathrm{~m} \times 0.68 \mathrm{~m} \times 0.88 \mathrm{~m}$, and four wheels with a diameter of $0.25 \mathrm{~m}$. Two steering wheels were installed at the rear, while the other two fixed-direction wheels were installed at the front. At a front wheel, a proximity switch sensor (speed sensor) was installed faced to the bolts mounted at the hub of the wheel. The bolts would trigger the sensor when the wheel was rolling. The travel speed could be calculated according to the signal of the proximity switch sensor. A fertilizer feeder was installed under a fertilizer box. A battery (DC 12V) and a controller was placed in the platform. Photoelectric sensors (target detection sensors) were installed on a fixed bar parallel to the ground at the front of the frame. The sensor could be moved in both horizontal and vertical directions manually. Each experiment target consisted of a rectangle board and a PVC tube to simulate the canopy and the trunk of a tree. 
When tests were conducted, the controller obtained the settings of the Tree-Width and Fertilizer-Volume per tree, the speed signal from the proximity switch sensor, and the tree target information from the photoelectric sensors. The controller then powered the fertilizer feeder to eject a certain amount of fertilizer.

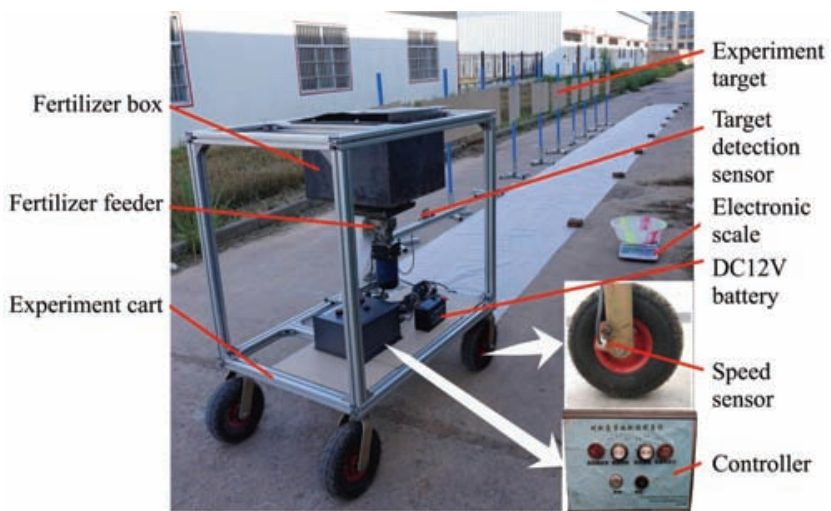

Figure 7 Experimental platform for laboratory tests

\subsection{Laboratory experiment for TDM of the dual-model} detection method

2.5.1 Test for distinguishing trunks from low-hanging canes

The ability of the controller to distinguish tree trunks from low-hanging canes was tested using the experimental platform. The diameters of Wolfberry tree trunks were always greater than $25 \mathrm{~mm}$, while the diameters of Wolfberry low-hanging canes were mostly less than $15 \mathrm{~mm}$ at the green cluster stage. Seven PVC tubes with different diameters were used to simulate tree trunks and canes. The diameters of the PVC tubes ranged at 5-40 mm with an increment of about $5 \mathrm{~mm}$. In each treatment, five PVC tubes with the same diameter were fixed on cement bases and uniformly placed in a line. The spacing between two adjacent PVC tubes was $1.5 \mathrm{~m}$. The experimental cart was manually driven along the PVC tube line at about $0.5 \mathrm{~m} / \mathrm{s}$. The actual speed was calculated by timing the cart using a stopwatch. The distance from the photoelectric sensor to the PVC tube was about $1 \mathrm{~m}$. The detection results were recorded by checking the existence of the fertilizer near each PVC tube.

\subsubsection{TDM test with simulated trunks of the same diameter}

To simulate Wolfberry tree trunks, ten PVC tubes with a diameter of $32 \mathrm{~mm}$ were used (Figure 8). Similar to the test in the section 2.5.1, the PVC tubes were uniformly placed in a line. The spacing between two adjacent PVC tubes was $1.5 \mathrm{~m}$. The Fertilizer-Volume variable of the controller was set as $600 \mathrm{~cm}^{3}$ per tree, while the Tree-Width was set as 0 to make the controller work in the TDM model. The bulk density of the granular fertilizer was $1.06 \mathrm{~g} / \mathrm{cm}^{3}$. The experimental cart was manually driven along the simulated tree trunks at about $0.3 \mathrm{~m} / \mathrm{s}$. The PVC tube was approximately $1 \mathrm{~m}$ from the sensor. The system controller detected the targets and controlled the fertilizer feeder to drop a certain amount of fertilizer near each simulated tree trunk. Then, the length $\left(L_{1}\right)$ and the offset $\left(L_{2}\right)$ of the fertilizer for each target were manually measured using a tape measure. The fertilizer for each target was collected and weighed using an electronic scale with accuracy of $1 \mathrm{~g}$ (LQ, 0-30 kg).

\subsection{Laboratory experiment for CDM of the dual-model} detection method

\subsubsection{Canopy gap detection test}

The test of the canopy gap detection was conducted in the lab. Simulated targets were placed in a row with different distances $\left(L_{3}\right)$ to simulate gaps within a tree and gaps between two adjacent trees
(Figure 9). According to the investigation, the gap within a Wolfberry tree was probably smaller than $20 \mathrm{~cm}$, and the gap between two adjacent trees was probably greater than $24 \mathrm{~cm}$. The distance $\left(L_{3}\right)$ ranged at $15-25 \mathrm{~cm}$ with an increment of $1-2 \mathrm{~cm}$. At each distance, there were 3-5 repetitions. Similarly, the experimental cart was manually driven along the simulated targets at about $0.3 \mathrm{~m} / \mathrm{s}$. The distance between the sensor and the target was about $1 \mathrm{~m}$. If a gap was determined by the controller to be the gap between two adjacent trees, the fertilizer would be ejected near the gap. Otherwise, there would be no fertilizer ejected. The detection results were recorded by checking the existence of the fertilizer near each gap.

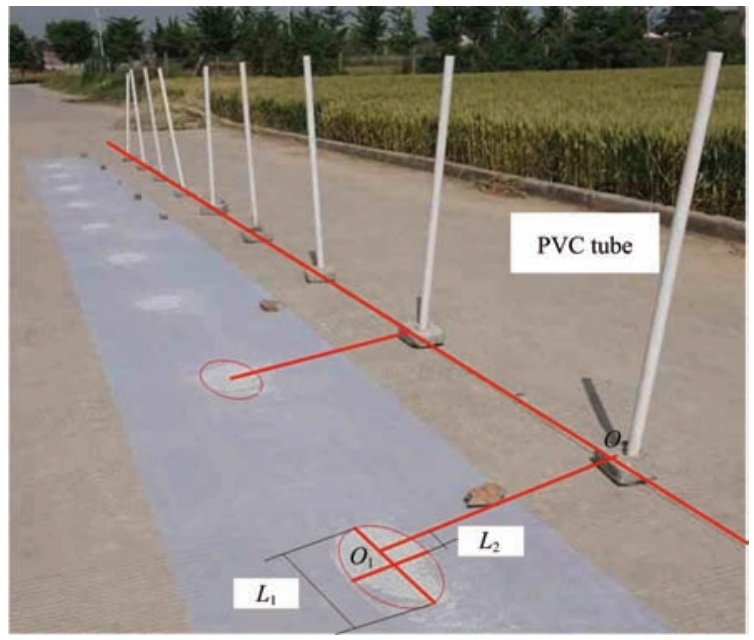

Note: $L_{1}$ is the length of fertilizer; $L_{2}$ is the center offset distance.

Figure 8 TDM test with simulated trunks of the same diameter

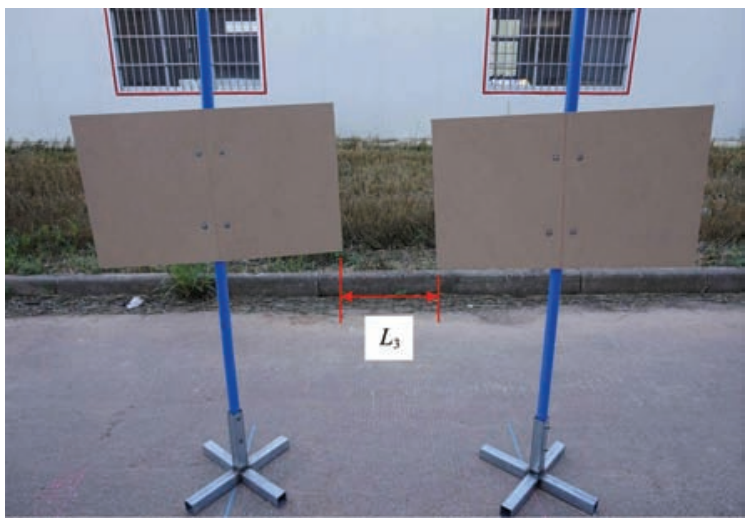

Note: $L_{3}$ is the length of the Gap.

Figure 9 Simulated gap within a tree or between two adjacent trees

\subsubsection{CDM test with simulated intermittent canopies}

Simulated intermittent tree canopies were used to test the controller in the Canopy Detection Model (CDM). Canopies with different widths $\left(L_{4}\right)$ were made using rectangular plywood sheeting (Figure 10). The widths of simulated canopies were divided into five groups in different experiments. The five groups were $30-40 \mathrm{~cm}, 50-70 \mathrm{~cm}, 80-100 \mathrm{~cm}, 110-130 \mathrm{~cm}$ and $140-160 \mathrm{~cm}$ The Tree-Width setting for the five groups were $30 \mathrm{~cm}, 60 \mathrm{~cm}$, $90 \mathrm{~cm}, 120 \mathrm{~cm}$ and $150 \mathrm{~cm}$, respectively. The center distance of two simulated intermittent trees was $2 \mathrm{~m}$. The CDM test with simulated intermittent canopies was conducted using the experimental platform at about $0.3 \mathrm{~m} / \mathrm{s}$. The distance from the photoelectric sensor to the target was about $1 \mathrm{~m}$ (Figure 10). The length of the fertilizer $\left(L_{1}\right)$ and the center offset distance $\left(L_{2}\right)$ were measured. There were five repetitions in the test. 


\subsubsection{CDM test with simulated continuous canopies}

The Canopy Detection Model (CDM) of the controller was tested using simulated continuous tree canopies. The continuous canopies were created by overlapping the rectangular plywood sheets on each simulated trees (Figure 11). The setting of the Tree-Width knob was chosen as $30 \mathrm{~cm}, 60 \mathrm{~cm}, 90 \mathrm{~cm}, 120 \mathrm{~cm}$, and $150 \mathrm{~cm}$, respectively. The experimental cart was driven along the rectangular plywood targets at about $0.3 \mathrm{~m} / \mathrm{s}$. The targets were about $1 \mathrm{~m}$ away from the photoelectric sensor. At each Tree-Width setting, ten continuous canopies were tested. Then, the center offset distance $\left(L_{2}\right)$, and the distance between the centers of adjacent piles of fertilizer $\left(L_{5}\right)$ were measured.

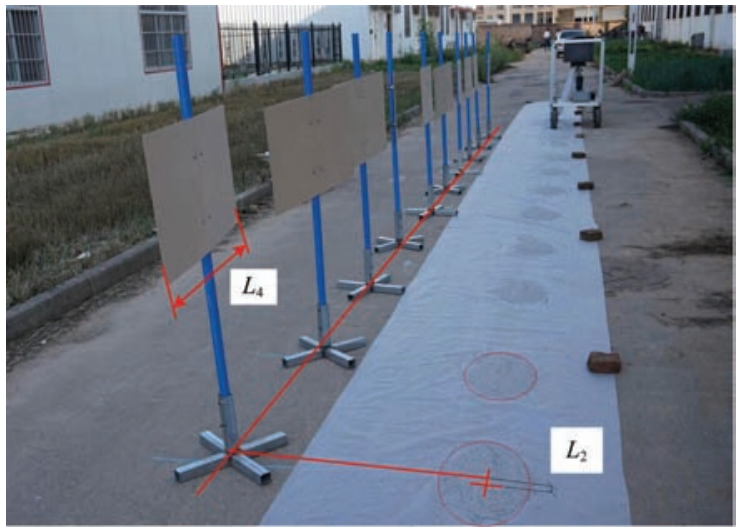

Note: $L_{4}$ is the width of canopy; $L_{2}$ is the center offset distance.

Figure 10 Simulated targets of intermittent canopies

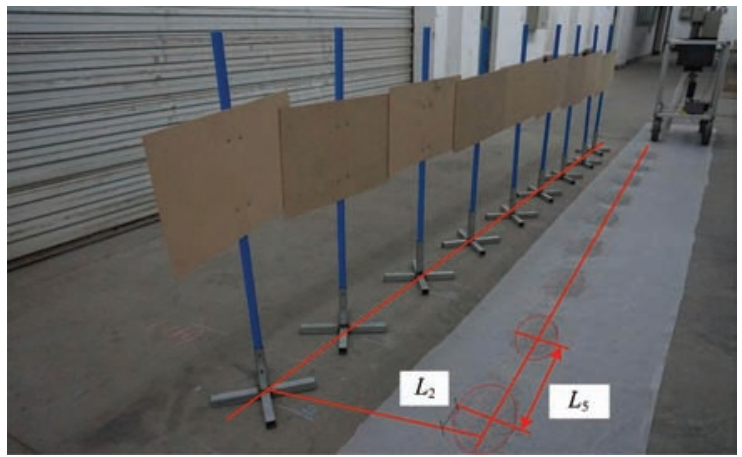

Note: $L_{2}$ is the center offset distance; $L_{5}$ is the distance between the centers of adjacent piles of fertilizer.

Figure 11 Simulated targets of continuous canopies

\subsection{Field experiment}

The target-oriented fertilization system was mounted on a test vehicle (Figure 12). A fatigue test was conducted before field tests. The system continuously worked for $48 \mathrm{~h}$ with simulated speeds and targets input. During the test the Fertilizer-Volume and Tree-Width settings were adjusted randomly. Then the system was tested in a Chinese Wolfberry orchard in Qinghai Province, China. The Wolfberry trees were early in mature growth stage with an average row width of $2.3 \mathrm{~m}$, and tree spacing of $1.2 \mathrm{~m}$. Some of their canopies were overlapped, and some were intermittent. The average tree canopy width was about $1.0 \mathrm{~m}$. The Tree-Width and Fertilizer-Volume settings were selected as $0.9 \mathrm{~m}$ and $600 \mathrm{~cm}^{3}$ per tree. A bag of granular fertilizer with a weight of $50 \mathrm{~kg}$ was put into the empty fertilizer box of the test vehicle. The bulk density of the granular fertilizer was $0.97 \mathrm{~g} / \mathrm{cm}^{3}$. The vehicle with the target-oriented fertilization system was driven at about $0.4 \mathrm{~m} / \mathrm{s}$ until all of the fertilizer in the box was applied on the orchard. The average speed was manually timed using a stopwatch and calculated. The total trees and fertilizer dropping events were counted.

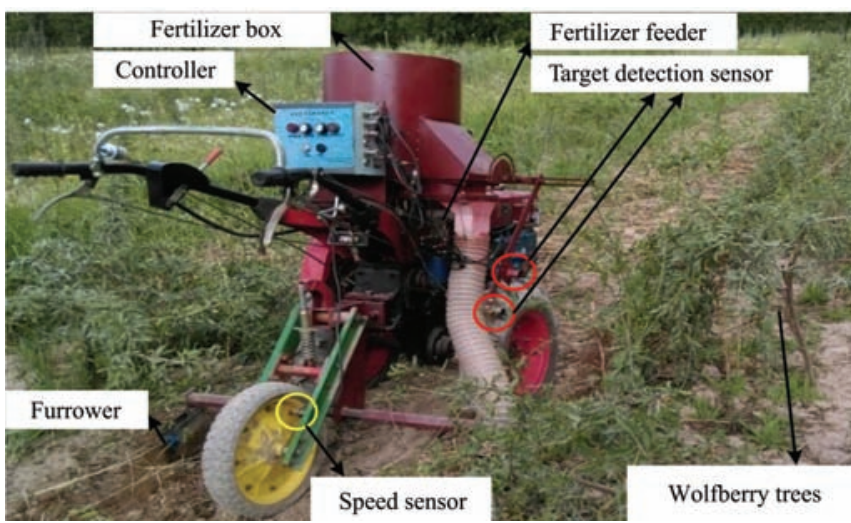

Figure 12 Field test in a Chinese Wolfberry orchard

\section{Results and discussion}

\subsection{Test results of TDM with simulated trunks of the same diameter}

3.1.1 Test for distinguishing trunks from low-hanging canes

The results of the test for distinguishing the tree trunks from the low-hanging canes showed that when the diameter of a target was smaller than $16 \mathrm{~mm}$, the excess fertilization was all ignored. When the diameter was greater than $25 \mathrm{~mm}$, the correct fertilization was all carried. Otherwise, if the diameter was close to the threshold of $20 \mathrm{~mm}$, the accuracy of judgement was $80 \%$ (Table 1).

The data indicated that the controller could reliably distinguish Chinese Wolfberry trunks from low-hanging canes at the green cluster growth stage when the diameter of a trunk was greater than $25 \mathrm{~mm}$ and the diameter of a low-hanging cane was smaller than $16 \mathrm{~mm}$. If the diameters of the trunks and the gap of the canopies were exactly in the middle of the two thresholds, the system could identify one from any of the two thresholds. For other Wolfberry trees, if the diameters of the canes and trunks were different from those of Chinese Wolfberry trees, the threshold could be adjusted as needed.

Table 1 Test results for distinguishing tree trunks from low-hanging canes

\begin{tabular}{cccc}
\hline $\begin{array}{c}\text { Diameter of } \\
\text { target } / \mathrm{mm}\end{array}$ & $\begin{array}{c}\text { Speed } \\
/ \mathrm{m}^{-1} \mathrm{~s}^{-1}\end{array}$ & $\begin{array}{c}\text { Number of fertilizer } \\
\text { ejection }\end{array}$ & $\begin{array}{c}\text { Accuracy } \\
\text { judgement } / \%\end{array}$ \\
\hline 5 & 0.46 & 0 & 100 \\
10 & 0.53 & 0 & 100 \\
16 & 0.46 & 0 & 100 \\
20 & 0.54 & 1 & 80 \\
25 & 0.48 & 5 & 100 \\
32 & 0.49 & 5 & 100 \\
40 & 0.48 & 5 & 100 \\
\hline
\end{tabular}

\subsubsection{TDM test with simulated trunks of the same diameter}

Table 2 showed the results of the TDM test with simulated trunks of the same diameter. The fertilizer volumes presented in the table were calculated according to the fertilizer weight and the fertilizer bulk density of $1.06 \mathrm{~g} / \mathrm{cm}^{3}$. The average Relative Error (RE) of the fertilizer volume was $2.7 \%$. The maximum length of the fertilizer was $42 \mathrm{~cm}$ with an average of $39.4 \mathrm{~cm}$, which could meet the requirement of $L_{1} \leq 50 \mathrm{~cm}$. The average offset distance in ten tests was $4.1 \mathrm{~cm}$. The results indicated that the target-oriented fertilization system exhibited high accuracy in fertilizer ejected volume and dropping location for upright targets. 
Table 2 Test results of TDM with simulated trunks of the same diameter

\begin{tabular}{cccccc}
\hline $\begin{array}{c}\text { Test } \\
\text { number }\end{array}$ & $\begin{array}{c}\text { Fertilizer } \\
\text { weight/g }\end{array}$ & $\begin{array}{c}\text { Fertilizer } \\
\text { volume/cm }\end{array}$ & $\begin{array}{c}\text { RE of } \\
\text { volume/\% }\end{array}$ & $\begin{array}{c}\text { Fertilizer } \\
\text { length/cm }\end{array}$ & $\begin{array}{c}\text { Center offset } \\
\text { distance } / \mathrm{cm}\end{array}$ \\
\hline 1 & 632 & 596.2 & 0.6 & 40 & 5 \\
2 & 616 & 581.1 & 3.1 & 38 & 6 \\
3 & 621 & 585.8 & 2.4 & 37 & 1 \\
4 & 611 & 576.4 & 3.9 & 40 & 3 \\
5 & 616 & 581.1 & 3.1 & 37 & 4 \\
6 & 614 & 579.2 & 3.5 & 38 & 1 \\
7 & 618 & 583.0 & 2.8 & 40 & 7 \\
8 & 623 & 587.7 & 2.0 & 42 & 3 \\
9 & 616 & 581.1 & 3.1 & 42 & 6 \\
10 & 624 & 588.7 & 1.9 & 40 & 5 \\
Mean & 619.1 & 584.1 & 2.7 & 39.4 & 4.1 \\
\hline
\end{tabular}

Note: RE is the abbreviation of Relative Error, RE of volume $=(600-$ Fertilizer volume) $/ 600$.

3.2 Laboratory experiment results for the CDM of the dual-model detection method

\subsubsection{Canopy gap detection}

Table 3 shows that the system could avoid the excess fertilization when a gap was less than $21 \mathrm{~cm}$. The correct fertilization was carried when a gap greater than $24 \mathrm{~cm}$. When the width of the gap was $22 \mathrm{~cm}$ or $23 \mathrm{~cm}$, which should be respectively determined as a gap within a tree and a gap between two adjacent trees, those judgements were not always correct. The data indicated that the system could reliably distinguish a gap within a tree from that between two adjacent trees when a gap between two adjacent trees greater than $24 \mathrm{~cm}$ and a gap less than $21 \mathrm{~cm}$, in the situation of the threshold of the gap distance was set to be $22 \mathrm{~cm}$.
Table 3 Test results of canopy gap detection

\begin{tabular}{cccc}
\hline $\begin{array}{c}\text { Width of the } \\
\text { gap/cm }\end{array}$ & $\begin{array}{c}\text { Numbers of fertilizer } \\
\text { ejection }\end{array}$ & $\begin{array}{c}\text { Times of } \\
\text { repetition }\end{array}$ & $\begin{array}{c}\text { The accuracy of gap } \\
\text { judgement/\% }\end{array}$ \\
\hline 15 & 0 & 3 & 100 \\
16 & 0 & 3 & 100 \\
18 & 0 & 3 & 100 \\
20 & 0 & 3 & 100 \\
21 & 0 & 3 & 100 \\
22 & 3 & 5 & 40 \\
23 & 3 & 5 & 60 \\
24 & 3 & 3 & 100 \\
25 & 3 & 3 & 100 \\
\hline
\end{tabular}

\subsubsection{CDM test with simulated intermittent canopies}

The results of the CDM test with simulated intermittent canopies at five different Tree-Width settings are shown in Figure 13. Figure 13a shows that $L_{2}$ exhibited a wavy trend, and its troughs appeared when the tree canopy widths equaled the Tree-Width settings. This trend indicates that reducing the interval of the Tree-Width settings could further improve the target-oriented accuracy. The greatest average center offset distance was $21.3 \mathrm{~cm}$ and the average offset distance in all tests was $13.1 \mathrm{~cm}$. This data indicates that this system can meet the requirements that the offset distance ranges from $-20 \mathrm{~cm}$ to $20 \mathrm{~cm}$. The average relative value of the center offset distance was less than $33.3 \%$ when the width of the target was less than $50 \mathrm{~cm}$. While the average relative value was less than $21 \%$ if the width was greater than $60 \mathrm{~cm}$ (Figure 13b). The average length of the fertilizer at different experimental tree widths was less than $39.7 \mathrm{~cm}$ (Figure 13c).

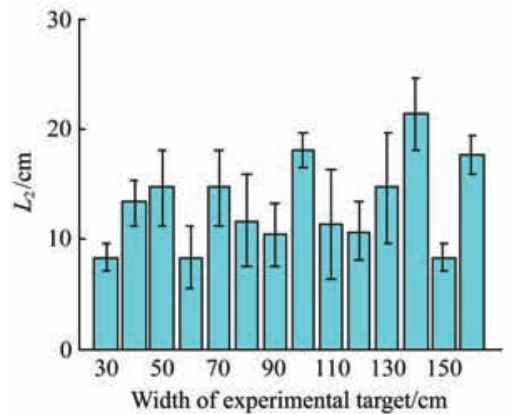

a. The center offset distance at different width of targets

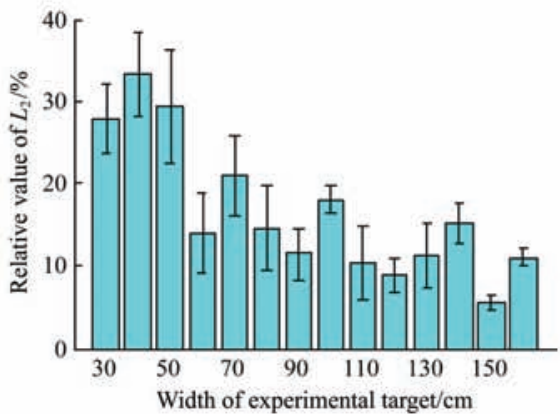

b. The relative value of center offset distance at different width of targets

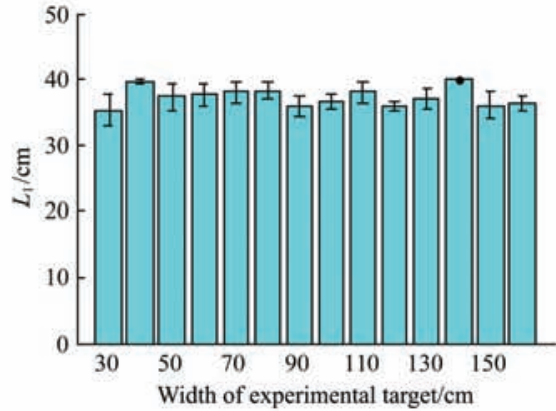

c. The length of fertilizer at different width of targets

Note: $L_{1}$ is the length of fertilizer; $L_{2}$ is the center offset distance.

Figure 13 Results of the CDM test with simulated intermittent canopies in five setting values

\subsubsection{CDM test with simulated continuous canopies}

The results of the CDM test with simulated continuous canopies are shown in Figure 14. The average of $L_{2}$ was less than $11.6 \mathrm{~cm}$ and the average offset distance in all tests was $9.1 \mathrm{~cm}$ (Figure 14a), and the average relative value of $L_{2}$ was less than $28.3 \%$ (Figure 14b). The average distance between the centers of adjacent piles of fertilizer $\left(L_{5}\right)$ consistently matched the Tree-Width settings (Figure 14c). The average of $L_{1}$ was less than $37.3 \mathrm{~cm}$ at each setting of the Tree-Width (Figure 14d). When the simulated targets are continuous, these results indicate that the system could successfully distinguish individual trees from continuous canopies, and implement target-oriented fertilization with high location and volume controlling accuracy.

\subsection{Field experiments}

In the fatigue test, the fertilization system successfully worked for $48 \mathrm{~h}$ without interruption. In the field experiment, the system ejected fertilizer 95 times for 92 Chinese Wolfberry trees using all of the $50 \mathrm{~kg}$ fertilizer. The average speed manually measured was $0.41 \mathrm{~m} / \mathrm{s}$. According to the Fertilizer-Volume setting of $600 \mathrm{~cm}^{3}$ per tree and the bulk density of $0.97 \mathrm{~g} / \mathrm{cm}^{3}$, the accuracy of ejected fertilizer volume was calculated to be $90.3 \%$. The bulk density of the fertilizer varies according to the object type. The fertilizer in this field experiment (Figure 12) had a poor ability to keep particles. Some particles became power due to the vibration of the tractor. This led to the difference of the fertilizer bulk density. In addition, when it was closed to the end of the experiment, the fertilizer feeder maybe not fully filled with fertilizer. The system setting kept the same as the preset value. Those are probably the reasons why the accuracy of ejected fertilizer volume was lower than the results listed in the Table 2. But the accuracy of $90.3 \%$ still meets 
the requirement.

The accuracy of target-oriented fertilization was $96.7 \%$ according to the test result that the system ejected fertilizer 95

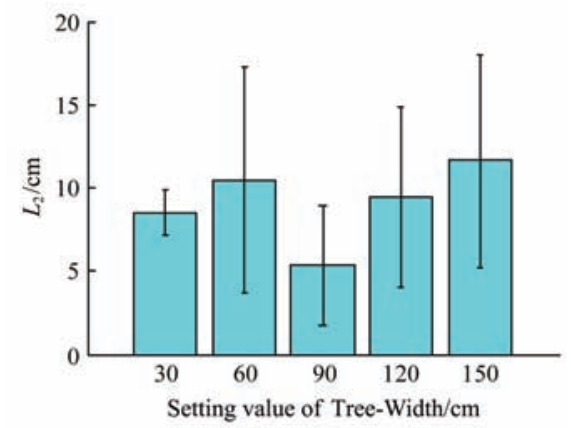

a. The center offset distance at five Tree-Width values

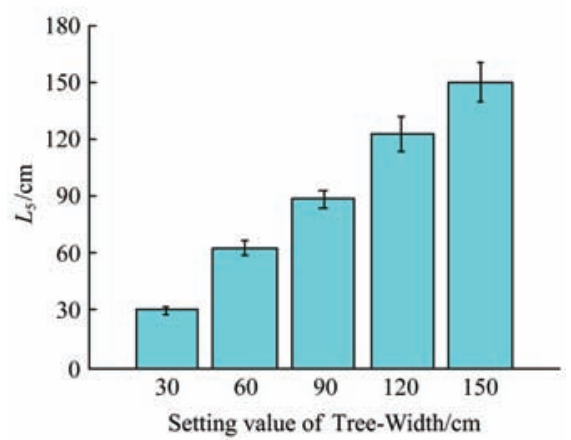

c. The distance between the centers of adjacent piles of fertilizer times for 92 Chinese Wolfberry trees. In the actual orchard with intermittent canopies and continuous canopies, the control system could accurately distinguish trees based on the CDM method.

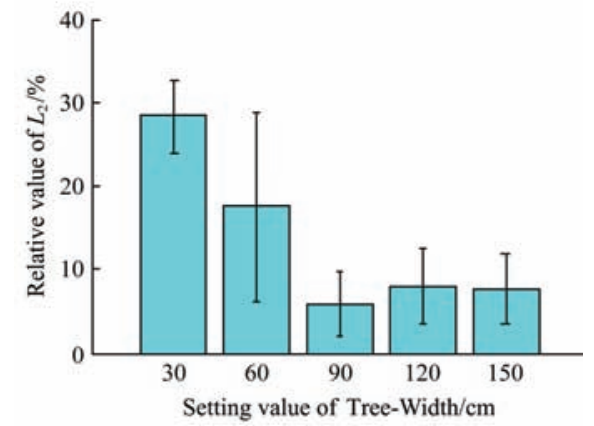

b. The relative value of center offset distance at five Tree-Width values

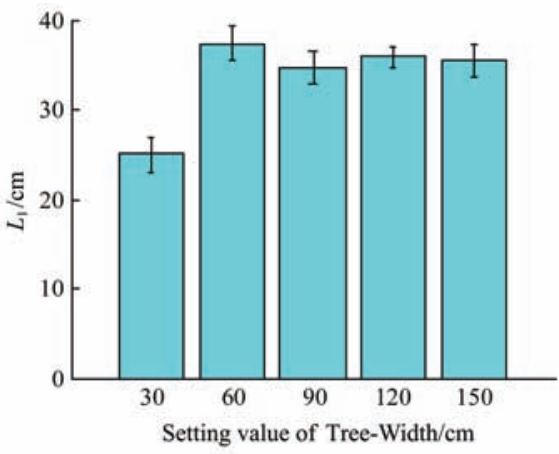

d. The length of fertilizer at five Tree-Width values

Note: $L_{2}$ is the center offset distance; $L_{5}$ is the distance between the centers of adjacent piles of fertilizer.

Figure 14 Results of the CDM test with simulated continuous canopies

\section{Conclusions}

A dual-model method for Wolfberry tree detection was proposed. The method included a Trunk Detection Model (TDM) and a Canopy Detection Model (CDM), which can be used to detect Wolfberry trees in real-time at the green cluster and mature stages, respectively.

A target-oriented fertilization system was designed based on the dual-model method using 1-3 photoelectric sensor(s) on each side. The controller not only could detect orchard trees and read the Fertilizer-Volume and Tree-Width settings for target-oriented variable rate fertilization, but also could monitor the fertilizer dropping and alert the operator when detecting incorrect fertilization.

The laboratory test results showed that the average center offset distances on the condition of detecting trunks, continuous canopies and discontinuous canopies is $4.1 \mathrm{~cm}, 9.1 \mathrm{~cm}$ and $13.1 \mathrm{~cm}$, respectively. The system could ignore the signals from canes when their diameters were less than $16 \mathrm{~mm}$, and also could determine the gaps within a tree when they were less than $21 \mathrm{~cm}$.

The orchard test results showed that the accuracy of target-oriented canopy was $96.7 \%$ at the mature stage, and the accuracy of fertilizer volume was $90.3 \%$.

The results indicated that the dual-model detection method could be used for Wolfberry trees or other trees with similar canopy change at different growth stages. However, uneven distribution of the Wolfberry tree canopies might affect the fertilization position accuracy and the detection accuracy of the dual-model method was affected by Wolfberry tree species, planting patterns, terrain difference, climate, etc. Further research will focus on field tests to investigate the influence of orchard tree characteristics on detection accuracy.

\section{Acknowledgments}

This work was supported by Shaanxi Science and Technology Projects (2017KJXX-54 and 2014KTCL02-15), Science and Technology Project of Northwest A\&F University (Z222021560) and the "Young Faculty Study Abroad Program" of Northwest A\&F University Scholarship Fund.

\section{[References]}

[1] Kim Y J, Kim H J, Ryu K H, Rhee J Y. Fertiliser application performance of a variable-rate pneumatic granular applicator for rice production. Biosyst Eng, 2008; 100(4): 498-510.

[2] Chattha H S, Zaman Q U, Chang Y K, Read S, Schumann A W, Brewster $\mathrm{G} R$, et al. Variable rate spreader for real-time spot-application of granular fertilizer in wild blueberry. Comput Electron Agric, 2014; 100: 70-78.

[3] Nanni M R, Povh F P, Demattê J A M, Oliveira R B De, Chicati M L, Cezar E. Optimum size in grid soil sampling for variable rate application in site-specific management. Sci Agric, 2011; 68(3): 386-392.

[4] Zhang X, Shi L, Jia X, Seielstad G, Helgason C. Zone mapping application for precision-farming: A decision support tool for variable rate application. Precis Agric, 2010; 11(2): 103-114.

[5] Yuan J, Liu C L, Li Y M, Zeng Q, Zha X F. Gaussian processes based bivariate control parameters optimization of variable-rate granular fertilizer applicator. Comput Electron Agric, 2010; 70(1): 33-41.

[6] Reyes J F, Esquivel W, Cifuentes D, Ortega R. Field testing of an automatic control system for variable rate fertilizer application. Comput Electron Agric, 2015; 113: 260-265.

[7] Back S-W, Yu S-H, Kim Y-J, Chung S-O, Lee K-H. An image-based application rate measurement system for a granular fertilizer applicator. Trans ASABE. American Society of Agricultural and Biological Engineers, 2014; 57(2): 679-687.

[8] Anastassiu H T, Vougioukas S, Fronimos T, Regen C, Petrou L, Zude M, et al. A computational model for path loss in wireless sensor networks in orchard environments. Sensors. Multidisciplinary Digital Publishing Institute, 2014; 14(3): 5118-5135. 
[9] Garcia A P, Cappelli N L, Umezu C K. Electrically driven fertilizer applicator controlled by fuzzy logic. Eng Agrícola, 2014; 34(3): 510-22.

[10] Castillo-Ruiz F J, Pérez-Ruiz M, Blanco-Roldán G L, Gil-Ribes J A, Agüera J. Development of a telemetry and Yield-Mapping system of olive harvester. Sensors, 2015; 15(2): 4001-4018.

[11] López-Granados F, Jurado-Expósito M, Álamo S, García-Torres L. Leaf nutrient spatial variability and site-specific fertilization maps within olive (Olea europaea L.) orchards. Eur J Agron, 2004; 21(2): 209-222.

[12] Kweon G, Grift T E. Feed Gate Adaptation of a Spinner Spreader for Uniformity Control. Biosyst Eng, 2006; 95(1): 19-34.

[13] Chan C W, Schueller J K, Miller W M, Whitney J D, Cornell J A. Error sources affecting variable rate application of nitrogen fertilizer. Precis Agric, 2004; 5(6): 601-616.

[14] Alva A K, Mattos D, Quaggio J A. Advances in Nitrogen Fertigation of Citrus. J Crop Improv, 2008; 22(1): 121-146.

[15] Schumann A W. Precise placement and variable rate fertilizer application technologies for horticultural crops. Horttechnology, 2010; 20(1): 34-40.

[16] Teixidó M, Font D, Pallejà T, Tresanchez M, Nogués M, Palacín J. Definition of linear color models in the RGB vector color space to detect red peaches in orchard images taken under natural illumination. Sensors, 2012; 12(6): 7701-7718.

[17] Phattaralerphong J, Sathornkich J, Sinoquet H. A photographic gap fraction method for estimating leaf area of isolated trees: assessment with 3D digitized plants. Tree Physiol, 2006; 26(9): 1123-1136.

[18] Phattaralerphong J, Sinoquet H. A method for 3D reconstruction of tree crown volume from photographs: assessment with 3D-digitized plants. Tree Physiol, 2005; 25(10): 1229-1242.

[19] Zhai C, Wang X, Zhao C, Zou W, Liu D, Mao Y. Orchard tree structure digital test system and its application. Math Comput Model, 2011; 54(3-4): 1145-1150.

[20] Zaman Q U, Schumann A W, Miller W M. Variable rate nitrogen application in Florida citrus based on ultrasonically-sensed tree size. Appl Eng Agric, 2005; 21(3): 331-335.

[21] Zaman Q U, Schumann A W. Performance of an ultrasonic tree volume measurement system in commercial citrus groves. Precis Agric, 2005; 6(5): 467-80.

[22] Gil E, Escolà A, Rosell J R, Planas S, Val L. Variable rate application of plant protection products in vineyard using ultrasonic sensors. Crop Prot, 2007; 26(8): 1287-1297.

[23] Escolà A, Planas S, Rosell J R, Pomar J, Camp F, Solanelles F, et al. Performance of an ultrasonic ranging sensor in apple tree canopies. Sensors, 2011; 11(3): 2459-2477.

[24] Zhai C, Yang S, Zhang B, Li H, Zhu R. Orchard toward-target variable-rate fertilizer system supporting fault alarming. Transactions of the CSAM, 2015; 46(10): 16-23. (in Chinese)

[25] Paulus S, Eichert T, Goldbach H E, Kuhlmann H. Limits of active laser triangulation as an instrument for high precision plant imaging. Sensors, 2014; 14(2): 2489-2509.

[26] Rosell Polo J R, Sanz R, Llorens J, Arnó J, Escolà A, Ribes-Dasi M, et al. A tractor-mounted scanning LIDAR for the non-destructive measurement of vegetative volume and surface area of tree-row plantations: A comparison with conventional destructive measurements. Biosyst Eng, 2009; 102(2): 128-134.

[27] Osterman A, Godeša T, Hočevar M, Širok B, Stopar M. Real-time positioning algorithm for variable-geometry air-assisted orchard sprayer. Comput Electron Agric, 2013; 98: 175-182.

[28] Escolà A, Rosell-Polo J R, Planas S, Gil E, Pomar J, Camp F, et al. Variable rate sprayer. Part 1 - Orchard prototype: Design, implementation and validation. Comput Electron Agric, 2013; 95: 122-135.

[29] Chen Y, Zhu H, Ozkan H E. Development of a variable-rate sprayer with laser scanning sensor to synchronize spray outputs to tree structures. Transactions of the ASABE, 2012; 55(3): 773-781.

[30] Sanz-Cortiella R, Llorens-Calveras J, Escolà A, Arnó-Satorra J, Ribes-Dasi M, Masip-Vilalta J, et al. Innovative LIDAR 3D dynamic measurement system to estimate fruit-tree leaf area. Sensors, 2011; 11(6): 5769-5791.

[31] Zhai C Y, Zhao C J, Wang X, Liu Y Z, Ge J S, Ma Y B, et al. Design and experiment of young tree target detector. Transactions of the CSAE, 2012; 28(2): 18-22. (in Chinese) 